\title{
Liposarcoma of the Spermatic Cord
}

\author{
Pierlesky Elion Ossibi, Hicham Anoune, Khalid El Haoudi, Karim Ibn Majdoub, \\ Imane Toughrai, Said Ait Laalim, Khalid Mazaz
}

Visceral Surgery Department, HASSAN II University Hospital, Fez, Morocco

Email: oselion@yahoo.fr

Received 1 July 2014; revised 2 August 2014; accepted 3 September 2014

Copyright (C) 2014 by authors and Scientific Research Publishing Inc.

This work is licensed under the Creative Commons Attribution International License (CC BY).

http://creativecommons.org/licenses/by/4.0/

C. (i) Open Access

\begin{abstract}
Few cases of Liposarcoma of the spermatic cord have been reported in the literature. This rare tumor represents $7 \%$ of malignant tumors of the spermatic cord. We report a case of an unusual liposarcoma of the spermatic cord, with respect to its sclerosing variant, occurring in a healthy looking 42 years old man. A wide local excision of the tumor was performed. Adjuvant radiotherapy may sometimes be effective on local recurrence. Even though this tumor evolves slowly, a prolonged follow up is required because of the risk of late recurrence.
\end{abstract}

\section{Keywords}

Liposarcoma, Spermatic Cord, Surgery

\section{Introduction}

Liposarcoma is a relatively uncommon mesenchymal tumor [1].

This tumor originating from the spermatic cord is exceptional, with approximately 100 cases reported in the literature [2]. Clinical diagnosis is difficult. Inguinal orchidectomy is the standard treatment for this tumor with a well-known local recurrence risk after surgery.

\section{Case Report}

A 42 years old man, with past history of right inguinal hernia repair 15 years back, presented with a left inguinoscrotal hernia.

The patient underwent exploratory surgery via a left inguinal canal approach, during which a hernia associated with a mass located on the spermatic cord was discovered (Figure 1).

We proceeded with tumorectomy of the mass associated with Lichtenstein repair of the hernia.

Histopathology examination of the tumorectomy specimen confirmed an undifferentiated liposarcoma or a high grade myxofibrosarcoma.

How to cite this paper: Ossibi, P.E., Anoune, H., El Haoudi, K., Majdoub, K.I., Toughrai, I., Laalim, S.A. and Mazaz, K. (2014) Liposarcoma of the Spermatic Cord. Case Reports in Clinical Medicine, 3, 518-520. 
Additional immunohistochemical study was performed showing a diffuse positivity of tumor cells staining with anti-MDM2 eliminating the diagnosis of high-grade myxofibrosarcoma and confirming the diagnosis of sclerosing variant of well differentiated liposarcoma (Figures 2(A)-(D)).

\section{Discussion}

Liposarcomas represent 7\% of tumors of the spermatic cord [3], they are rare tumors The largest series being that of Coleman et al. [4], with 47 cases reported from 1982 to 2001. The few case reports reveal a predominance of retroperitoneal locations followed by the pelvis (bladder-prostate-vagina-cervix). Very few cases of paratesticular sarcomas and spermatic cord have been reported in the literature.

These tumors are rarely diagnosed and form a spectrum of lesions of variable aggressiveness.

In the literature, this tumor affects adult patients with variable ages ranging from 16 to 88 years [5] [6].

Clinically, liposarcoma of the spermatic cord manifests in the form of a firm, painless nodular mass variable in size. It can be enormous.

Histologically, World Health Organization (WHO) classification of soft tissue tumors recognizes five subtypes of liposarcoma which can be divided in three distinct entities by their locations, their epidemiology, their clinical expressions and their imaging profiles [7] [8].

Differential diagnosis of a lipoma with a well-differentiated liposarcoma can be difficult. However, over expression of MDM2 and/or CDK4 establishes the diagnosis, although this over expression is neither $100 \%$ sensitive (MDM2) or specific (CDK4), making the assessment of surgical margins delicate [8].

The recommended treatment for liposarcoma of the spermatic cord consists of a surgical excision of the mass with radical orchidectomy via an inguinal canal [9] [10].

Radiation therapy may be given in addition to surgical excision for large tumors whose complete resection might not be possible. But it remains the choice treatment to prevent local recurrences.

Radiotherapy reduces the local recurrence rate without direct impact on overall survival [11].

Chemotherapy, on the contrary, has not proven its efficacy on these tumors [9] [11]. Liposarcoma evolves slowly; it is rather dominated by the frequency of relapses reported in $50 \%$. This supports the need for local monitoring which could be prolonged [9].

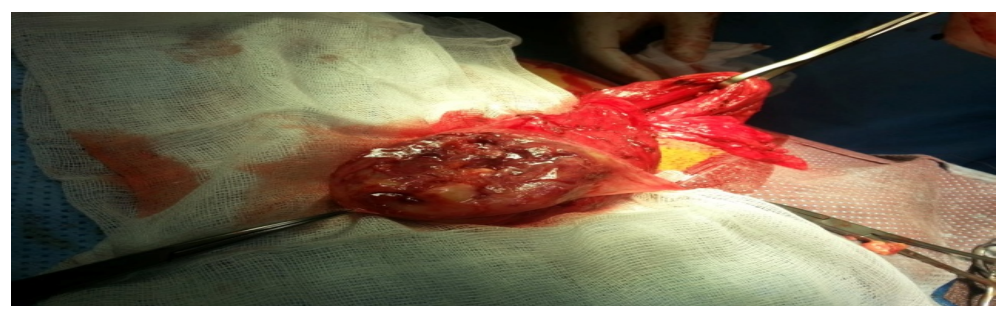

Figure 1. Mass developed at the expense of the spermatic cord.

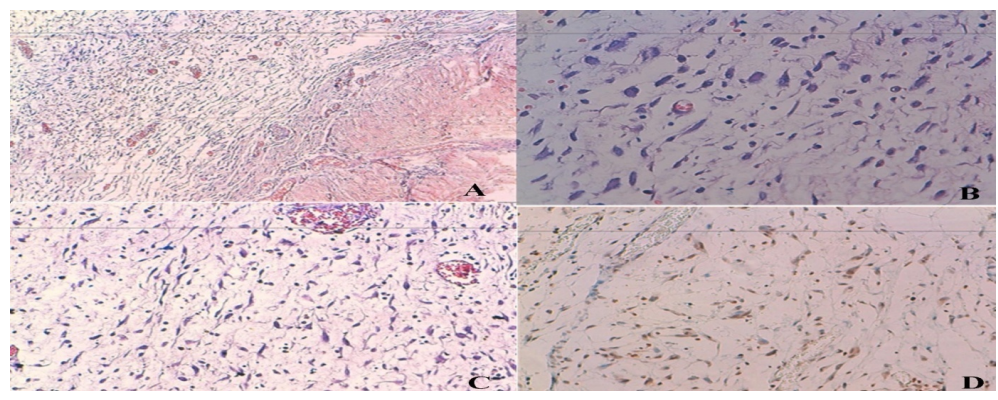

Figure 2. Histological images. (A) Myxoid stroma with fusocellular proliferation rich in capillaries with thickened walls (HES $\times 10$ ); (B) Atypical tumor cells with irregular, hyperchromatic and pleomorphic nuclei with a few mitotic figures (HES $\times 40$ ); (C) Fusocellular tumor proliferation on a rich fibromyxoid base (HES $\times 20$ ); (D) Nuclear expression of tumor cells labelled with anti MDM2 antibodies in immunohistochemistry. 


\section{Conclusions}

The liposarcoma of the spermatic cord is a rare tumor. Diagnosis of this tumor depends on histological examination.

The recommended treatment is inguinal orchidectomy. Although the prognosis is quite favorable, prolonged monitoring is required because of the risk of local recurrence which may occur very late.

\section{References}

[1] Schwartz, S.L., Swierzewski III, S.J., Sondak, V.K. and Grossman, H.B. (1995) Liposarcoma of the Spermatic Cord: Report of 6 Cases and Review of the Literature. Journal of Urology, 153, 154-157. http://dx.doi.org/10.1097/00005392-199501000-00055

[2] Dündar, M., Erol, H., Koçak, I. and Kaçar, F. (2001) Liposarcoma of the Spermatic Cord. Urologia Internationalis, 67, 102-103. http://dx.doi.org/10.1159/000050959

[3] Vorstman, B., Blok, N.L. and Politano, V.A. (1984) The Management of Spermatic Cord Liposarcomas. Journal of Urology, 131, 66-69.

[4] Coleman, J., Brennan, M.F., Alektiar, K. and Russo, P. (2003) Adult Spermatic Cord Sarcomas: Management and Results. Annals of Surgical Oncology, 10, 669-675. http://dx.doi.org/10.1245/ASO.2003.11.014

[5] Pozza, D., Masci, P., D’ottavio, G. and Zappavigna, D. (1987) Spermatic Cord Liposarcoma in a Young Boy. Journal of Urology, 137, 306-308.

[6] Sogani, P.C., Brabstald, H. and Whitmore, J.R. (1978) Spermatic Cord Sarcoma in Adults. Journal of Urology, 120, 301-305.

[7] Evans, H.L. (1979) Liposarcoma: A Study of 55 Cases with a Reassessment of Its Classification. American Journal of Surgical Pathology, 3, 507-523. http://dx.doi.org/10.1097/00000478-197912000-00004

[8] Dei Tos, A.P. and Pedeutour, F. (2002) Atypical Lipomatous Tumour/Well Differentiated Liposarcoma. Dedifferentiated Liposarcoma. In: Fletcher, D.M., Krishnan Unni, K. and Mertens, F., Eds., WHO Classification of Tumours. Pathology and Genetics of Tumours of Soft Tissue and Bone. International Agency for research on cancer Press, Lyon, 35-39.

[9] Vorstman, B., Blok, N.L. and Politano, V.A. (1984) The Management of Spermatic Cord Liposarcomas. Journal of Urology, 13, 66-69.

[10] Rabbani, F., Wright, J. and McLoughlin, M. (1997) Sarcomas of the Spermatic Cord: Significance of Wide Local Excision. Canadian Journal of Urology, 4, 366-369.

[11] Mondaini, N., Palli, D., Saieva, C., Nesi, G., Franchi, A., Ponchietti, R., Tripodi, S., Miracco, C., Meliani, E., Carini, M., Liviu, L., Zanna, I., Trovarelli, S., Marino, V., Vignolini, G., Pomara, G., Orlando, V., Giubilei, G., Selli, C. and Rizzo, M. (2005) Clinical Characteristics and Overall Survival in Genitourinary Sarcomas Treated with Curative Intent: A Multicenter Study. European Urology, 47, 468-473. http://dx.doi.org/10.1016/j.eururo.2004.09.013 
Scientific Research Publishing (SCIRP) is one of the largest Open Access journal publishers. It is currently publishing more than 200 open access, online, peer-reviewed journals covering a wide range of academic disciplines. SCIRP serves the worldwide academic communities and contributes to the progress and application of science with its publication.

Other selected journals from SCIRP are listed as below. Submit your manuscript to us via either submit@scirp.org or Online Submission Portal.
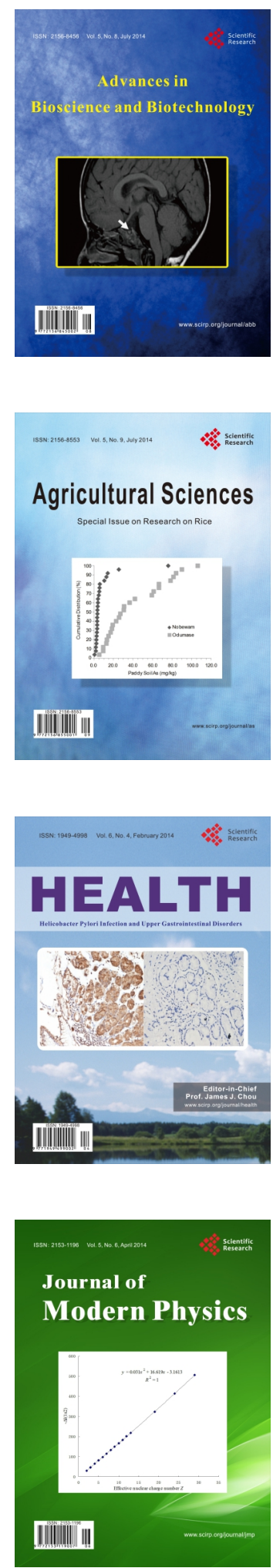
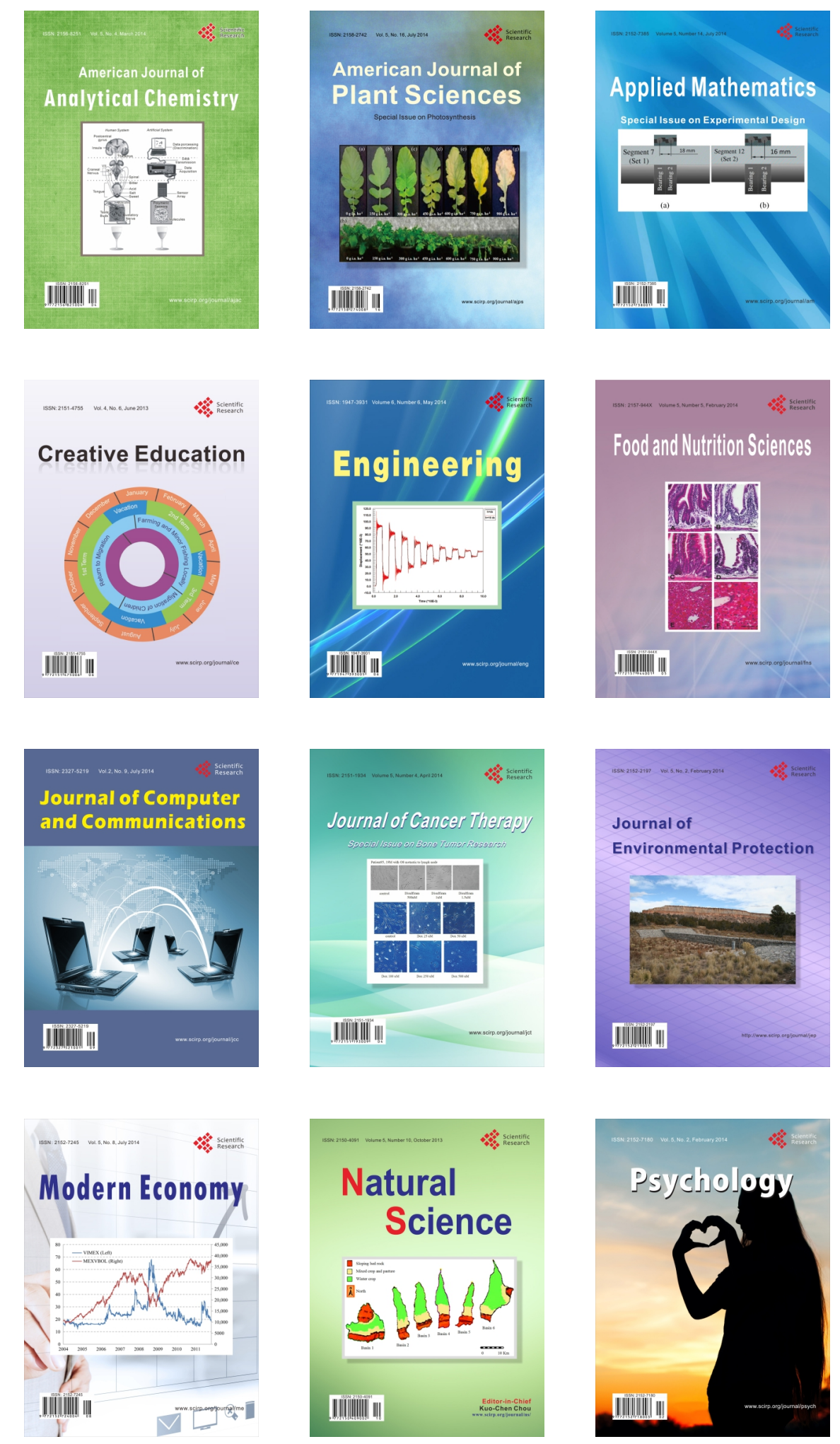